\title{
Evidence of deontic reasoning in 3- and 4-year-old children
}

\author{
DENISE DELLAROSA CUMMINS \\ University of Arizona, Tucson, Arizona
}

\begin{abstract}
Deontic reasoning is reasoning about what one may, ought, or ought not do in a given set of circumstances. Virtually all of our social institutions and child-rearing practices presume the capacity to reason about deontic concepts, such as what is permitted, obligated, or prohibited. Despite this, very little is known about the development of deontic reasoning. Two experiments were conducted that contrasted children's reasoning performance on deontic and indicative reasoning tasks (i.e., the reduced array selection version of the Wason card selection task). Like adults, children as young as 3 years of age were found to adopt a violation-detecting strategy more often when reasoning about the deontic case than when reasoning about the indicative case. These results indicate that violation detection emerges as an effective deontic reasoning very early in human development.
\end{abstract}

Deontic reasoning is reasoning about what one may, ought, or must not do in a given set of circumstances (Hilpinen, 1971, 1981; Manktelow \& Over, 1991). Virtually all of our social institutions-from schools and movie theaters to the justice system-presuppose a capacity to understand and reason about what is permitted, obligated, prohibited, or advised. Failure to reason effectively about deontic concepts can have disastrous consequences, including scolding, expulsion, legal action, and even incarceration.

So fundamental is the presumed capacity to reason about deontic concepts that it underlies most of our childrearing practices. Adults typically try to guide and structure children's behavior by requiring them to adhere to conditional deontic rules, such as "If you want to play outside, you must wear a coat," or "All kindergartners must stay in the playground." In order to behave appropriately, children must determine which actions are permitted, obligated, or prohibited, and under which conditions. Moreover, reference to social rules appear in children's justifications of their behavior as early as 24 months of age (Dunn, 1988). Reasoning about deontic situations, therefore, constitutes a major issue in children's lives. Yet despite this, very little is known about the development of deontic reasoning and its relation to other types of reasoning.

In recent years, deontic reasoning has loomed large in the adult psychological reasoning literature. In contrast to their performance on statistical reasoning (see, e.g., Kahneman, Slovic, \& Tversky, 1982), indicative reasoning (e.g., Wason \& Johnson-Laird, 1972), and mathematical or scientific problem-solving tasks (e.g., Chi, Feltovich, \& Glaser, 1981), adults typically perform consistently and well on tasks requiring deontic reasoning (e.g., Cheng

Correspondence should be addressed to D. D. Cummins, Psychology Department, California State University, $6000 \mathrm{~J}$ Street, Sacramento, CA 95819 (e-mail: dcummins@saclink.csus.edu).
\& Holyoak, 1985, 1989; Griggs \& Cox, 1983; Manktelow \& Over, 1991, 1995). In fact, so robust and reliable is performance on deontic reasoning tasks that numerous proposals have been put forth to explain it.

The first explanation is pragmatic reasoning schema theory (Cheng \& Holyoak, 1985, 1989; Cheng, Holyoak, Nisbett, \& Oliver, 1986). According to this theory, adults excel at deontic reasoning because deontic concepts constitute classes of frequently encountered situations for which collections of domain-specific, goal-oriented rules are induced. One such schema, the permission schema, captures the relationship between actions and preconditions in a collection of rules, such as "If the precondition is satisfied, then the action may be taken." A second theoretical explanation is social exchange theory, which analyzes deontic reasoning in terms of cost/benefit analysis and cheater detection (Cosmides, 1989; Cosmides \& Tooby, 1994). These strategies are proposed to be innate, having been selected during the evolution of our species to facilitate reasoning about social exchange (cooperative action for mutual benefit). A third theory analyzes deontic reasoning in terms of violation-detection strategies that are innate and domain-specific for reasoning about deontic situations (Cummins, in press). Finally, a fourth theory explains the deontic effect in terms of the construction and manipulation of mental models on the basis of subjective utility (Manktelow \& Over, 1990, 1991, 1995).

Despite the very considerable differences among these theoretical explanations, they all have one thing in common, and that is the central role afforded violation detection in deontic reasoning. As Gigerenzer and Hug (1992) point out, a crucial part of reasoning deontically is appreciating the necessity of detecting violations of deontic rules. For example, in the case of permissions, one must ensure that no one has taken a specified action without having also satisfied some conditions (e.g., "If you want to take a book out of the library <permitted action $>$, you must have a valid library card < condition $>$ "). 
In the case of obligations, one must ensure that no one has avoided doing what is obligated (e.g., "If you lost a library book < condition >, you must pay $\$ 25$ in fines $<$ obligatory action>"). In the case of prohibitions, one must ensure that no one has done something forbidden (e.g., "No one may slide down the slide backward").

In contrast, what constitutes optimal performance on indicative reasoning tasks (where reasoners are asked to test the truth of a rule) is the subject of some controversy. Traditionally, violation detection played a central role in normative theories of indicative reasoning, because observing a violation of an indicative rule (hypothesis) disproves the rule (e.g., finding a white raven disproves the rule "all ravens are black") and hence provides incontrovertible proof of its truth content (Popper, 1959). Seeking confirming evidence, which is the typical strategy employed by adults on indicative reasoning tasks, was considered at best a bias in the reasoning process and at worst an error (Evans, 1989; Wason, 1968). Recently, however, this assumption has been challenged by the argument that a "seek confirmation" strategy can be optimal under certain circumstances (Oaksford \& Chater, 1994).

However one measures the normative value of the strategies that adults typically employ on indicative and deontic reasoning tasks, the fact remains that when reasoning about deontic rules, adults spontaneously adopt a violation-detection strategy, and when reasoning about indicative rules, they spontaneously adopt confirmationseeking strategies (see Cummins, in press, for a review of this literature). Very little is known, however, about when these distinct strategies emerge in childhood, owing primarily to the difficulty in developing tasks that work with populations younger than 6 or 7 years of age (see, e.g., Girotto, Light, \& Colbourne, 1988; Komatsu \& Galotti, 1986; Light, Blaye, Gilly, \& Girotto, 1989; Light, Girotto, \& Legrenzi, 1990; Overton, Ward, Noveck, Black, \& O'Brien, 1987; Sodian, Zaitchik, \& Carey, 1991). In this paper, I describe the results of two experiments in which this issue was investigated with the use of a task that allows children's reasoning to be directly compared with that of adults. The task is based on the Wason reducedarray card selection task, which requires the reasoner to choose whether to inspect potentially confirming or violating cases when testing a rule. The rules used here are "All squeaky mice are in the house" and "All squeaky mice must stay in the house." The first is an indicative rule concerning a factual state of affairs, whereas the second is a deontic rule that specifies expected behavior. Discovering squeaky mice who are outside the house falsifies the indicative rule; that is, it proves that the rule is false. But such discovery does not disprove the deontic rule. Rather, it identifies violators who have disobeyed the rule and, presumably, will face appropriate consequences. The procedure employed is a modification of one used by Girotto et al. (1988) with 9- to 10-year-old children. Girotto et al. reported that children in this age group were more likely to adopt a violation-detection strategy when testing the rule "All buzzing bees must stay in the house" than when testing the indicative rule "All buzzing bees are in the house."

Experiment 1 is a replication of Girotto et al. with a much younger age group, 3- and 4-year-old children. In Experiment 2, the tasks were modified in order to rule out competing explanations of the deontic effect. If violationdetection does emerge early as a deontic reasoning strategy, we would expect the same pattern of results as is typically reported in the adult literature; that is, the children should show a greater propensity to choose to inspect potentially violating cases when reasoning about a deontic rule than they do when reasoning about an indicative rule.

\section{EXPERIMENT 1}

The methodology in this experiment replicates the crucial components of Girotto et al. (1988), which is itself a modification of Wason's reduced array selection task (Johnson-Laird \& Wason, 1970; Wason, 1968). In this task, reasoners are presented with a conditional rule (If $\langle p\rangle$, then $\langle q\rangle$ ) in universally quantified form (All $<p>$ are $\langle q>$ ), and are asked to test the rule by choosing whether to examine potentially confirming instances $(q)$ or potentially violating instances $(-q)$. In order to induce a deontic interpretation of the rule in the deontic task, the deontic reasoning task included a story in which an authority (Queen Mouse) uttered a prescriptive rule concerning what the mice should do, and the rule contained the modal "must" ("All squeaky mice MUST stay in the house"). In contrast, the story in the indicative task described a hypothesis-testing situation in which the experimenter uttered a descriptive rule (no modal) whose epistemic status needed to be tested ("All squeaky mice ARE in the house"). It was predicted that children would be more likely to adopt a violation-detection strategy when reasoning about a deontic rule than when reasoning about an indicative rule.

\section{Method}

Subjects. The subjects were 3 - and 4-year-old children ( $n=44$ and 40 , respectively) recruited from day-care centers and preschools in Tucson. The age data for the 3-year-olds were as follows: range = $3,1-3,11, \mathrm{Mdn}=3,6$ in the deontic condition, and range $=2,11-3,11$, $\mathrm{Mdn}=3,5$ in the indicative condition. For the 4-year-olds, range $=$ $4,0-4,11, \mathrm{Mdn}=4,4$ in the deontic condition, and range $=4,0-4,11$, $\mathrm{Mdn}=4,3$ in the indicative condition. Parental consent was obtained for each participant prior to participation in the study.

Materials. Materials included (1) 10 yellow rubber mice, 5 of which squeaked when squeezed and 5 of which did not, (2) a "mouse house" $19.5 \times 28 \times 25 \mathrm{~cm}$, constructed from a large cardboard box and spray-painted white, with a detachable $26 \times 24 \mathrm{~cm}$ door, (3) backyard play props, including a toy slide, picnic table, and tree. The backyard equipment was arranged next to the house so that mice inside and outside the house were equally visible and reachable.

One squeaky and one nonsqueaky mouse (the latter will hereafter be referred to as quiet mice) were reserved for demonstration purposes. The remaining eight mice were divided evenly between the house and the backyard, so that two quiet mice and two squeaky mice appeared in each location. The mice were identical in appearance. Detection of their difference required squeezing them. 
Procedure. Children were tested individually in their day-care center or preschool. The location of the house (on the child's right or left) was counterbalanced between subjects. Sessions were videotaped. All sessions began with the following verbatim protocol:

$<$ Name of child >, I'd like you to play a pretend game with me. I'd like you to pretend that this is a house, and these mice Ipointing to mice] live there. That's their home. Some of the mice have gone out into the backyard to play, see? They're having a good time, sliding down the slide, and playing on the picnic table, and around the tree. So these mice are in the house [pointing] and these mice are in the backyard playing [pointing]. At night everybody goes in the house, and they close the door [door is affixed] so that they're nice and safe and nothing can get them. [Door removed.] Now < name of child >, would you do me a quick favor? Would you point to the mice that are in the house? And would you point to the mice that are in the backyard?

I have something else very interesting to tell you about these mice. See how they all look exactly alike? But they're really different because some of them squeak [demo squeaky mouse squeezed] and some of the them are quiet [demo quiet mouse squeezed]. This is a squeaky mouse [squeezed] and this is a quiet mouse [squeezed]. Squeeze this mouse and you'll see it makes a lot of noise [child was allowed to squeeze squeaky mouse]. Now squeeze this one [child was allowed to squeeze quiet mouse]. See? It's really quiet. It doesn't make any noise at all.

The deontic protocol continued as follows:

I have something else interesting to tell you. Sometimes in the evening, the mice like to go out in the backyard to play. But when the squeaky mice play, they get really excited and they start to squeak, like this [squeezing mouse repeatedly]. And then you know what happens? The neighborhood cat hears that squeaking, and he comes running, and pounces, and chases the mice all around. [Stuffed toy cat appeared, chasing the mouse.] So it's not safe for the squeaky mice outside. It's only safe for the quiet mice. Now, the Queen Mouse heard about this. [Minnie Mouse doll appeared.] The Queen Mouse is their mama, and she makes important rules that everyone has to follow. So let's listen carefully because she's going to make a rule and we're going to have to make sure nobody disobeys. Queen Mouse: "Oh, I'm so worried about the squeaky mice because of that cat. It's not safe outside for the squeaky mice because of that cat, so I'm going to make a rule, and the rule is ALL SQUEAKY MICE MUST STAY IN THE HOUSE. YES, ALL SQUEAKY MICE HAVE TO STAY IN THE HOUSE."

She said all the squeaky mice must stay in the house, so let's make sure nobody is breaking that rule, OK? Let's make sure no one is disobeying the Queen. Which mice should we check, those that are in the house, or those that are in the backyard playing?

The order of the query (inside first or outside first) was counterbalanced between subjects.

The indicative condition protocol continued after the general introduction with the following:

Now, I'm going to tell you something, but I might be tricking you, so listen carefully. I know something. I know that ALL THE SQUEAKY MICE ARE IN THE HOUSE. YES, ALL THE SQUEAKY MICE ARE IN THE HOUSE." Was I tricking you? Which mice should we squeeze to find out whether I was tricking you, the ones that are in the house, or the ones that are in the backyard playing?

The order of the query (inside first or outside first) was counterbalanced between subjects.

The child was required first to point and state verbally which mice had to be squeezed to test the rule, and was then allowed to actually squeeze them.

\section{Results and Discussion}

All children chose to squeeze only the mice that they had in fact pointed to in order to answer the initial query. The number of children in each age group who indicated that the mice in the backyard had to be checked (i.e., the $-q$ violating case) is shown in Table 1.
Table 1

Number Correct ( $-q)$ Selections Among 3- and 4-Year-Olds in Deontic and Indicative Reasoning Contexts (Experiment 1)

\begin{tabular}{ccccc}
\hline & \multicolumn{4}{c}{ Reasoning Context } \\
\cline { 2 - 5 } Age & \multicolumn{2}{c}{ Deontic } & & Indicative \\
\cline { 2 - 5 } & $-\mathrm{q}$ & $n$ & $-\mathrm{q}$ & $n$ \\
\hline 3 & 15 & 22 & 7 & 22 \\
4 & 17 & 20 & 7 & 20 \\
\hline
\end{tabular}

Among 3-year-olds, $68 \%$ selected the $-q$ case in the deontic condition, whereas only $32 \%$ did so in the indicative condition, a doubling in performance that was statistically reliable $\left[G^{2}(1)=5.95, p<.02\right]$. Among 4-yearolds, $85 \%$ selected the $-\mathrm{q}$ case in the deontic case, whereas only $35 \%$ did so in the indicative condition, a difference that was also statistically reliable $\left[G^{2}(1)=11.03, p<\right.$ $.01]$. These results replicate those of Girotto et al. (1988) with a much younger age group, thereby indicating that children as young as 3 years of age adopt a violationdetection strategy when reasoning about deontic rules. In contrast, they do not adopt this type of strategy when reasoning about indicative rules; they adopt instead a confirmation-seeking strategy. In other words, by the age of 3, the deontic-indicative distinction is already apparent in children's reasoning strategies. The magnitude of this performance difference is approximately the same as that observed in adult performance (see, e.g., Cheng \& Holyoak, 1985, 1989; Griggs \& Cox, 1983; Manktelow \& Over, 1991). This suggests that a distinction between reasoning about what one should do (deontic) and determining the epistemic status of a rule (indicative) emerges quite early in development and persists into adulthood.

\section{EXPERIMENT 2}

Although the results of Experiment 1 are compelling, they do not provide unequivocal evidence for the deontic effect due to the structure of Girotto et al.'s (1988) embedding stories. It might have been the case that children in the deontic condition were more likely to check the mice who were outside because of the danger posed by the lurking cat, and not because of any particular propensity to adopt a violation-detection strategy only when reasoning about deontic situations. To rule out this possibility, the procedure was modified to include the cat and all of its ramifications in the indicative story condition. A second modification was the removal of the reference to "tricking" on the part of the experimenter. Although children as young as 2 years of age are capable of deliberately lying about their actions, reliable and consistent reasoning about acts of deception and false beliefs in others are difficult to demonstrate in populations younger than 4 (see Leekam, 1992; Leslie, 1994; and Leslie \& Roth, 1993, for reviews of this literature). Instead, Minnie Mouse was introduced as a potentially unreliable character who stated that all the squeaky mice were in the house, and 
the children were asked to find out whether or not she was wrong. Although this seems to require reasoning about false beliefs, this procedure has been used successfully with 3-year-olds on false belief tasks (Wellman \& Bartsch, 1988; Zaitchik, 1991). The major difference between this and the standard false belief task is that the children do not know where the squeaky mice really are, and so they are not required to choose between the current reality (where the mice really are) and a counterfactual belief (where someone falsely believes them to be).

If the results of Experiment 1 were in fact due to greater propensity to seek violations when reasoning about deontic rules, then the results of Experiment 1 should be replicated. If the difference in reasoning strategies observed in Experiment 1 was instead due to concern about keeping the mice safe from the cat, then children should show a preference for checking the outside $(-q)$ mice in both the deontic and the indicative conditions.

\section{Method \\ Subjects. Subjects were 3- and 4-year-old children $(n=70$ and 40 , respectively) recruited from day-care centers and preschools in Tucson. The age data for the 3 -year-olds were as follows: range $=$ $2,6-3,11, \mathrm{Mdn}=3,6$ in the deontic condition, and range $=2,11-3,11$, $\mathrm{Mdn}=3,5$ in the indicative condition. For the 4-year-olds, range $=$ $4,0-4,11, \mathrm{Mdn}=4,6$ in the deontic condition, and range $=4,0-4,11$, $\mathrm{Mdn}=4,6$ in the indicative condition. Parental consent was obtained for each participant prior to participation in the study. \\ Materials. The same materials as those in Experiment 1 were used here. Counterbalancing was not completely even among 3-year-olds, owing to uneven class sizes. \\ Procedure. All sessions were audiotaped. The deontic story was identical to the one used in Experiment 1 . The indicative story con- dition was modified so that the section following the introduction continued thus: \\ I have something else interesting to tell you. Sometimes in the evening, the mice like to go out in the backyard to play. But when the squeaky mice play, they get really excited and they start to squeak, like this [squeezing mouse repeatedly]. And then you know what happens? The neighborhood cat hears that squeaking, and he comes running, and pounces, and chases the mice all around. [Stuffed toy cat appeared, chasing the mouse.] So it's not safe for the squeaky mice outside. It's only safe for the quiet mice. Now, I'd like you to meet someone. This is Minnie Mouse. [Minnie Mouse stuffed animal appeared.] Minnie likes to tell kids things, so let's listen carefully because we're going to have to figure out whether what she says is right or wrong. Minnie Mouse: "Hi, <name of child>! I know something about the mice. Uh, huh! I know that IT'S NOT SAFE OUTSIDE FOR THE SQUEAKY MICE BECAUSE OF THAT CAT, SO ALL THE SQUEAKY MICE ARE IN THE HOUSE! YES, ALL THE SQUEAKY MICE ARE IN THE HOUSE!" Now, I wonder if she could be wrong about that. Let's find out. Which mice should we squeeze to find out if she's wrong, the mice that are inside the house, or the mice that are in the backyard playing?}

\section{Results and Discussion}

One 3-year-old in the deontic condition chose to squeeze all of the mice despite having indicated "outside" during the initial query, so his data were excluded from analysis. The remaining number of children correctly selecting the $-\mathrm{q}$ case (backyard) is shown in Table 2 . In the deontic condition, $62 \%$ of the 3 -year-olds selected the mice playing in the backyard in the deontic condition, whereas only $37 \%$ did so in the indicative con-
Table 2

Number Correct ( - q) Selections Among 3- and 4-Year-Olds in Deontic and Indicative Reasoning Contexts (Experiment 2)

\begin{tabular}{|c|c|c|c|c|}
\hline \multirow[b]{3}{*}{ Age } & \multicolumn{4}{|c|}{ Reasoning Context } \\
\hline & \multicolumn{2}{|c|}{ Deontic } & \multicolumn{2}{|c|}{ Indicative } \\
\hline & $-q$ & $n$ & $-q$ & $n$ \\
\hline 3 & 21 & 34 & 13 & 35 \\
\hline 4 & 16 & 20 & 6 & 20 \\
\hline
\end{tabular}

dition, a relationship that was significant $\left[G^{2}(1)=4.23\right.$, $p<.05$ ]. Similarly, $80 \%$ of the 4 -year-olds correctly indicated that the mice playing in the backyard needed to be checked, whereas only $30 \%$ did so in the indicative condition, a statistically reliable effect $\left[G^{2}(1)=10.60, p<\right.$ $.01]$. Comparison of these percentages with the ones obtained in Experiment 1 suggest that the modification in the indicative story condition had little effect on the children's performance. In Experiment 1, 32\% of the 3-year-olds selected $-\mathrm{q} ; 37 \%$ did so here. Among 4-year-olds, $35 \%$ selected the $-\mathrm{q}$ case, whereas $30 \%$ did so here. Given the similar levels of performance on the indicative-content task across the two experiments, it seems reasonable to conclude that the crucial factor influencing children's reasoning was the deontic context, and not the danger posed by the cat in the stories. Moreover, the difference in performance levels between the conditions is particularly striking when one considers how similar the reasoning rules were-that is, "ALL SQUEAKY MICE MUST STAY IN THE HOUSE" versuS "ALL SQUEAKY MICE ARE IN THE HOUSE." The only difference is to be found in the deontic interpretation afforded by the deontic story context and the presence of the modal "must."

\section{GENERAL DISCUSSION}

The data reported here clearly show that children as young as 3 years of age adopt a violation-detection strategy when reasoning about deontic situations and a confirmation-seeking strategy when reasoning about indicative tasks. These results strongly suggest that these domain-specific reasoning strategies emerge early in development, being in place by at least the 3 rd year of life.

These results are consistent with the explosion of research showing evidence of early emerging domainspecific reasoning capacities, including reasoning about the permanence and rigidity of objects as well as constraints on their motion (Baillargeon, 1987, 1994; Spelke, 1994), physical causality (Leslie, 1984; Leslie \& Keeble, 1987), biomechanical movement (Bertenthal, 1984, 1985), the abstract concept of number and arithmetic operations (Starkey, Spelke, \& Gelman, 1990; Wynn, 1992), the meaning of emotional facial expressions (Campos \& Stenberg, 1981), the reciprocal nature of certain social interactions (Vandell \& Wilson, 1987), ontological category (Carey, 1985; Keil, 1986), and certain aspects of moral reasoning (Miller, 1986; Miller \& Bersoff, 1988; Turiel, 1983, 1989). 
These results do not provide unequivocal support for the stronger view, taken by many developmentalists in explaining their results, that early emergence occurs because deontic reasoning strategies are innate. The possibility exists that by the age of 3 , young children have experienced a sufficient number of deontic situations to enable them to induce a suitably abstract schema. This is an explanation that is consistent with pragmatic reasoning schema theory in that it attributes early emergence to the frequency and urgency with which deontic reasoning situations present themselves during early childhood. In other words, there is ample opportunity to induce a schema for reasoning about deontic situations. Alternatively, the children in this study might have been reasoning analogically, detecting sufficient similarity between the mice's deontic context and ones that they themselves have experienced to allow them to retrieve relevant knowledge concerning the outcomes of obedient and disobedient behaviors from memory.

There are other reasons, however, to believe that deontic reasoning strategies might in fact constitute an innate part of our cognitive architecture. Cummins (in press) argues that the deontic effect provides a unique glimpse into the innate structure of the human reasoning architecture. At the heart of this position lies an evolutionary argument. Evolutionary theory is based on the assumption that there is a causal relationship between the adaptive problems that a species repeatedly encounters during its evolution and the design of its phenotypic structures. My position is that one of the largest selective pressures faced during the evolution of our reasoning architecture was the need to reason effectively about dominance hierarchies, and that survival within the dominance hierarchy requires effective deontic reasoning strategies.

In functional terms, a dominance hierarchy is simply the statistical observation that "particular individuals in social groups have regular priority of access to resources ... in competitive situations" (Clutton-Brock \& Harvey, 1976). It is a characteristic of nearly all mammalian and avian societies. The role of dominance is most pronounced in situations characterized by high levels of competition for resources, such as high population density or the onset of breeding season. This suggests that strong evolutionary pressure has favored the evolution of reasoning capacities aimed specifically at recognizing and exploiting social dominance relations, a conclusion that is supported by empirical observation.

Consider first the concept of permission. Those who currently dominate resources determine who may engage in which activities when, and they punish transgressors. For example, dominant male primates monopolize reproduction opportunities by aggression against females and subordinate males who are caught consorting (de Waal, 1982). To avoid agonistic encounters, it is therefore crucial to reason effectively about what is permitted and what is forbidden. It is in the interest of subordinates, on the other hand, to broaden their access to available resources. In other words, it is in their interest to move up in rank. Among primates, dominance ranking is not cor- related with size. Instead, one's rank in the hierarchy depends crucially on the ability to form and maintain strong alliances, and alliances are formed and maintained on the basis of reciprocal obligations, another deontic concept. For example, Cheney and Seyfarth (1990, pp. 67-69) have reported that vervet monkeys are more likely to respond to calls from non-kin during agonistic encounters if the caller has groomed them recently; they also form the strongest alliances with individuals who groom them most often. This pattern of behavior suggests an appreciation of an obligation structure wherein grooming obligates the groomee to intervene on the part of the groomer in future agonistic encounters, while giving the groomee grounds to expect such assistance, and hence permission to engage in encounters he or she would otherwise avoid.

Primate field studies, therefore, suggest that sensitivity to deontic content plays a crucial role in determining an individual's fate within primate social groups. The need to reason effectively about permission/prohibition structures and reciprocal obligations looms exceedingly large in primate communities. Failure to adhere to permission and obligation structures leads to banishment from the social group, a situation that can have disastrous consequences for survival. Clearly, if our reasoning architecture evolved in response to the need to reason effectively about adaptively crucial problems, and if survival depends crucially on staying within the social group, then few problems carry greater survival consequences among social species than those involving deontic contents. This strongly suggests that deontic reasoning strategies-or their precursors - are part of our primate genetic heritage. For this reason, we would expect to observe the early emergence of violation-detection as a domain-specific deontic reasoning strategy, just as we have observed here with 3 -year-old children.

There are two important contrasts with regard to the evolutionary explanation offered by Cummins (in press) and the social exchange theory proposed by Cosmides and Tooby. The first is whether the deontic effect is species specific - that is, particular to humans. Social exchange theory explains the deontic effect in terms of a cheater-detection reasoning strategy shaped and selected by evolutionary forces specifically to facilitate reasoning about social exchange, an activity that is most developed among humans and that appeared most strikingly among humans during the Pleistocence (Cosmides, 1989; Cosmides \& Tooby, 1989, 1992, 1994). The evidence cited from the primatology literature suggests that violation-detection is not specific to our species. The second is whether the deontic effect reflects a strategy that is specialized for reasoning about social exchange or for deontic situations broadly defined. Deontic situations are any situations that require reasoning about what is socially obliged, permitted, prohibited, cautioned, or advised (what one ought to do). Social exchange is just one type of deontic situation. It is difficult to frame the current tasks in terms of social exchange, since there is no cooperation between individuals for mutual benefit; instead, there is only obedience to an authority's pre- 
scriptive rule. For this reason, perhaps the most parsimonious explanation of the results reported here is that the early emergence of a domain-specific violationdetection strategy reflects an innate propensity for recognizing deontic rules and the necessity of seeking violations of them.

\section{REFERENCES}

BAILlARGEON, R. (1987). Object permanence in 31/2-and $4 \frac{1}{2} 2$-monthold infants. Developmental Psychology, 23, 655-664.

BAILlargeon, R. (1994). How do infants learn about the physical world? Current Directions in Psychological Science, 3, 133-140.

BertenthaL, B. I. (1984). Infant sensitivity to figural coherence in biomechanical motions. Journal of Experimental Child Psychology, 37, 213-230.

Bertenthal, B. I. (1985). The development of sensitivity to biomechanical motions. Child Development, 56, 531-543.

Campos, J. J., \& Stenberg, C. (1981). Perception, appraisal, and emotion: The onset of social referencing. In M. Lewis \& L. Rosenblum (Eds.), Infant social cognition: Empirical and theoretical considerations (pp. 273-314). Hillsdale, NJ: Erlbaum.

CAREY, S. (1985). Conceptual change in childhood. Cambridge, MA: MIT Press.

Cheney, D. L., \& Seyfarth, R. M. (1990). How monkeys see the world. Chicago: University of Chicago Press.

Cheng, P. W., \& Holyoak, K. J. (1985). Pragmatic reasoning schemas. Cognitive Psychology, 17, 391-416.

CHENG, P. W., \& HOLYOAK, K. J. (1989). On the natural selection of reasoning theories. Cognition, 33, 285-313.

Cheng, P. W., Holyoak, K. J., Nisbett, R. E., \& Oliver, L. M. (1986) Pragmatic vs syntactic approaches to training deductive reasoning Cognitive Psychology, 18, 293-328.

Chi, M. T. H., Feltovich, P. J., \& Glaser, R. (1981). Categorization and representation of physics problems by experts and novices. $C o g$ nitive Science, 6, 121-152.

Clutron-Brock, T. H., \& Harvey, P. H. (1976). Evolutionary rules and primate societies. In P. P. G. Bateson \& R. A. Hinde (Eds.), Growing points in ethology (pp. 195-238). Cambridge: Cambridge University Press.

Cosmides, L. (1989). The logic of social exchange: Has natural selection shaped how humans reason? Studies with the Wason selection task. Cognition, 31, 187-276.

Cosmides, L., \& TOOBY, J. (1989). Evolutionary psychology and the generation culture: Part II. Case study: A computational theory of social exchange. Ethology \& Sociobiology, 10, 51-97.

Cosmides, L., \& ToobY, J. (1992). Cognitive adaptations for social exchange. In J. Barkow, L. Cosmides, \& J. Tooby (Eds.), The adapted mind: Evolutionary psychology and the generation of culture (pp. 163-228). New York: Oxford University Press.

COSMIDES, L., \& TOOBY, J. (1994). Beyond intuition and instinct blindness: Toward an evolutionarily rigorous cognitive science. Cognition, 50, 41-77.

Cummins, D. D. (in press). Evidence for the innateness of deontic reasoning. Mind \& Language.

DE WAAL, F. B. M. (1982). Chimpanzee politics. New York: Harper \& Row.

DunN, J. (1988). The beginnings of social understanding. Oxford: Basil Blackwell.

Evans, J. ST. B. (1989). Bias in human reasoning. Hillsdale, NJ: Erlbaum.

Gigerenzer, G., \& Hug, K. (1992). Domain-specific reasoning: Social contracts, cheating, and perspective change. Cognition, 43,127 171 .

Girotto, V., Light, P., \& Colbourn, C. J. (1988). Pragmatic schemas and conditional reasoning in children. Quarterly Journal of Experimental Psychology, 40A, 469-482.

Griggs, R. A., \& Cox, J. R. (1983). The effects of problem content and negation on Wason's selection task. Quarterly Journal of Experimental Psychology, 35A, 519-533.

HILPINEN, R. (1971). Deontic logic: Introductory and systematic readings. Boston: Reidel/Kluwer.

HilPINEN, R. (1981). New studies in deontic logic: Norms, actions, and the foundations of ethics. Boston: Reidel/Kluwer.

JoHNSON-LAIRD, P. N., \& WASON, P. C. (1970). Insight into a logical relation. Quarterly Journal of Experimental Psychology, 22, 49-61.

Kahneman, D., Slovic, P., \& Tversky, A. (1982). Judgement under uncertainty: Heuristics and biases. Cambridge: Cambridge University Press.

KEIL, F. C. (1986). The acquisition of natural kind and artifact terms. In W. Demopoulos \& A. Marras (Eds.), Language learning and concept acquisition: Foundational issues (pp. 133-153). Norwood, NJ: Ablex.

Komatsu, L. K., \& GalotTI, K. M. (1986). Children's reasoning about social, physical, and logical regularities: A look at two worlds. Child Development, 57, 413-420.

LeEKaM, S. R. (1992). Believing and deceiving: Steps to becoming a good liar. In S. J. Ceci, M. DeSimone Leichtman, \& M. E. Putnick (Eds.), Cognitive and social factors in early deception (pp. 47-62). Hillsdale, NJ: Erlbaum.

LESLIE, A. M. (1984). Spatiotemporal continuity and the perception of causality in infants. Perception, 13, 287-305.

LeSLIE, A. M. (1994). ToMM, ToBY, and agency: Core architecture and domain specificity. In L. A. Hirshfel \& S. A. Gelman (Eds.), Mapping the mind: Domain specificity in cognition and culture. Cambridge: Cambridge University Press.

LESLIE, A. M., \& KeEBLE, S. (1987). Do six-month-old infants perceive causality? Cognition, 25, 265-288.

LeSLIE, A. M., \& Roth, D. (1993). What autism teaches us about misrepresentation. In S. Baron-Cohen, H. Tager-Flusberg, \& D. J. Cohen (Eds.), Understanding other minds: Perspectives from autism (pp. 83111). Oxford: Oxford University Press.

Light, P., Blaye, A., Gilly, M., \& Girotto, V. (1989). Pragmatic schemas and logical relations in 6- to 8-year-old children. Cognitive Development, 4, 49-64.

Light, P., GirotTo, V., \& Legrenzi, P. (1990). Children's reasoning on conditional promises and permissions. Cognitive Development, $\mathbf{5}$, 369-383.

MankTelow, K. I., \& Over, D. E. (1990). Deontic thought and the selection task. In K. J. Gilhooly, M. T. Keane, R. H. Logie, and G. Erdos (Eds.), Lines of thinking (Vol. 1, pp. 153-164). Chichester, U.K.: Wiley.

MaNKTELOW, K. I., \& OVER, D. E. (1991). Social roles and utilities in reasoning with deontic conditionals. Cognition, 39, 85-105.

MankTelow, K. I., \& Over, D. E. (1995). Deontic reasoning. In S. E. Newstead \& J. St. B. Evans (Eds.), Perspectives on thinking and reasoning (pp. 91-114). Hillsdale, NJ: Erlbaum.

Miller, J. (1986). Early cross-cultural commonalities in social explanation. Developmental Psychology, 22, 514-520.

Mill.er, J., \& BERSOFF, D. M. (1988). When do American children and adults reason in social conventional terms? Developmental Psychology, 24, 366-375.

OAKSFORD, M., \& Chater, N. (1994). A rational analysis of the selection task as optimal data selection. Psychological Review, 101, 608-631.

Overton, W., Ward, S., Noveck, I., Black, J., \& O'Brien, D. (1987). Form and content in the development of deductive reasoning. Developmental Psychology, 23, 22-30.

POPPER, K. (1959). The logic of scientific discovery. London: Hutchinson.

Sodian, B., Zaitchik, D., \& CaRey, S. (1991). Young children's differentiation of hypothetical beliefs from evidence. Child Development, 62, 753-766.

SPELKE, E. (1994). Initial knowledge: Six suggestions. Cognition, 50, 431-445.

Starkey, P., Spelke, E. S., \& Gelman, R. (1990). Numerical abstraction by human infants. Cognition, 36, 97-127.

TURIEL, E. (1983). The development of social knowledge: Morality and convention. Cambridge: Cambridge University Press.

TuRIEL, E. (1989). Domain-specific social judgments and domain ambiguities. Merrill-Palmer Quarterly, 35, 89-114. 
VANDELL, L., \& WILSON, K. S. (1987). Infant's interactions with mother, sibling, and peer: Contrasts and relations between interaction systems. Child Development, 58, 176-186.

WASON, P. C. (1968). Reasoning about a rule. Quarterly Journal of Experimental Psychology, 20, 273-281.

WASON, P. C., \& JoHNSON-LAIRD, J. L. (1972). Psychology of reasoning: Structure and content. London: Batsford.

Wellman, H. M., \& BarTSCH, K. (1988). Young children's reasoning about beliefs. Cognition, 30, 239-277.
WYNN, K. (1992). Addition and subtraction by human infants. Nature, $358,749-750$

ZaITCHIK, D. (1991). Is only seeing really believing? Sources of true beliefs in the false belief task. Cognitive Development, 6, 91-103.

(Manuscript received October 13, 1995; revision accepted for publication February 11, 1996.) 